\title{
Lime treatment of slightly clayey coarse soil for the control of internal erosion by suffusion
}

\author{
Radja Elandaloussi \& Abdelkrim Bennabi \\ Université Paris-Est, Institut de recherche en constructibilité (ESTP-IRC) \\ Jean-Claude Dupla \& Jean Canou \\ Université Paris-Est, Laboratoire Navier-Cermes
}

Ahmed Benamar

Université du Havre, Laboratoire LOMC

Phillipe Gotteland

Federation Nationale des Travaux Publics

ABSTRACT: The cost of an earth dike is even lower than soils used for its construction came from deposits close to the site. In parts of France, stocks of coarse and slightly clayey soils are not used because they are prone to internal erosion by suffusion. In order to reduce or control internal erosion in this kind of soils containing relatively low amounts of fines, a lime treatment was considered. For this purpose, an experimental laboratory test, based on the use of a soil column, has been developed. It reproduces the flow of water through a reconstituted soil, having characteristics similar to that of natural soils, and compacted at $95 \%$ of the optimum Proctor. The soil was treated with two percentages of lime $(1 \%, 3 \%)$ and erosion tests were performed at different curing times $(1,7,28$ and 90 days). The developed device has been instrumented in order to measure different parameters such as turbidity, flow and pore water pressure.

The results are expressed in terms of eroded mass and soil permeability if erosion occurs or, alternatively, in terms of fracturing conditions. A comparison is performed between the results of different tests carried on non-treated and treated soils in different conditions. The lime treatment induces a significant change in the hydraulic behavior of the soil, significantly reducing the phenomenon of suffusion and fracturing the soil at high hydraulic gradients.

\section{INTRODUCTION}

The cost and the construction delays of a dam are less important when the materials come from deposits close to the construction site.

The materials used in the construction of an earth dam are classified into two categories: permeable materials (sands and gravels), less permeable categories (clays).

The dam construction type generally depends on the proportions of the previously mentioned materials. In fact, the construction of homogeneous structures is recommended where there is close to the construction site a large amount of permeable materials. In the opposite case, when close to the construction site there is a significant amount of less permeable materials, the future dams are constructed with a waterproof core.

On the other hand, if, at the same site, are permeable and less permeable materials available, choosing the type of dams depends on its significance.

It should be noted that the slopes of homogeneous structures (built with low-permeability materials) are lower than those of dams with a waterproof core (Josseaume, 1970). It follows that the volume of materials used in the configuration of dams constructed with waterproof core is less important, nevertheless the cost is still high because the construction of filters is expensive. For this purpose and for some works, the homogeneous dams solution remains the most economical.

However, in reality it's not always evident to reuse all the excavated materials. Some soils excavated in areas near the site are unusable in the dam body due to their instability to internal erosion (specifically the suffusion). These soils, which are coarse, have a very wide range of particle size and are of low permeability. They can be used in the case of homogenous dams. This type of soil is transported to landfill and replaced with materials brought from distant area. Enhance these coarse extracted soil would respect the costs and delays of projects and especially to be part a sustainable development approach which aims zero waste zero borrowing.

Suffusion is a complex phenomenon of internal erosion which is characterized by the detachment and transport of fine particles through the pore space of a coarser matrix. This phenomenon occurs under the effect of an internal flow.

The assessments of soils sensibility to this phenomenon continue to be the subject of several studies. Some studies were carried in the case of fine sandy soils or coarse soils but not on a wide range of particle size that contains clay and coarse particles. 
This instability criteria to the suffusion can be geometric or hydraulic. The most commonly used are those of Terzaghi (1939), Kezdi (1969), Kenney and Lau (1985) and Burenkova (1993).

Some criteria were more conservative than the others. Li (2008) defined a streamlined to gather the most reliable geometric and hydraulic criteria to better predict the problem of instability.

On the other hand, to allow the lime treatment, it's essential to take an interest in fine soils (clay soils) and the possibility of lime treatment. For this moment some mechanical tests were performed, De Bel et al. (2013) observed a low evolution of unconfined compressive strength for a MLD soil (soil from Marche-les Dames, Belgium) treated with $3 \%$ of lime during the 100 first days of curing. Also Maubec 2010 doesn't observe any improvement during the 60 first days.

Further studies were carried out on the behavior of a clay soil treated with lime in the erosion field. Haghighi noted that clay soil treated with lime didn't collapse like untreated soil.

For the present study, the coarse soil was reconstituted in the laboratory similarly to a natural soil of a landfill located south of France. This soil contains a small amount of clay and one wonders if a lime treatment is able to improve its resistance to suffusion. We present, also, an experimental study, developed to improve the resistance of a coarse soil against the suffusion phenomenon. The purpose of this study is to treat the soil with lime and to compare the results of suffusion tests with those obtained for the untreated soil.

\section{EXPERIMENTAL PROCEDURE AND MATERIALS}

\subsection{Experimental device}

The developed device consists of a suffusion column, an effluent collection system, an automated hydraulic loading device, a measurement system and a control device and acquisition data (Figure 1).

The measurement system allows following the temporal evolution of pore pressure throughout the column, turbidity, flow of water and the mass of eroded particles.

The suffusion column, cylindrical, is Plexiglas allowing a visual inspection during the test. This column allows testing samples with $250 \mathrm{~mm}$ diameter $16 \mathrm{~mm}$ height. It is arranged vertically and is supplied by a water tank for an upward flow.

The tank position depends on the hydraulic gradient that we wish to apply, knowing that the hydraulic gradient represents the piezometric head drop per unit length.
The effluent is collected in order to determine the total mass of eroded particles.

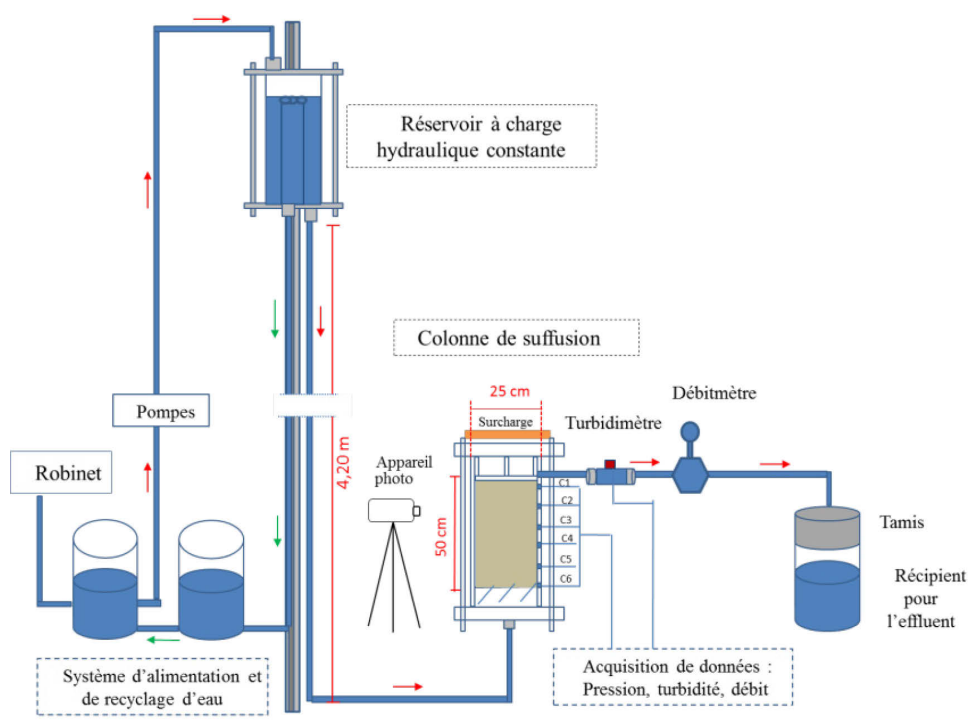

Figure 1. Schematic diagram of the suffusion test

\subsection{Materials}

The coarse soil has been reconstituted in the laboratory very close to the natural soil from a landfill lacated south of France (Figure 2). The natural soil is gravelly sandy soil with fine Class B according to French standard NF P 11-300.

This soil is essentially characterized by a discontinuous grading curve (Figure 3 ).

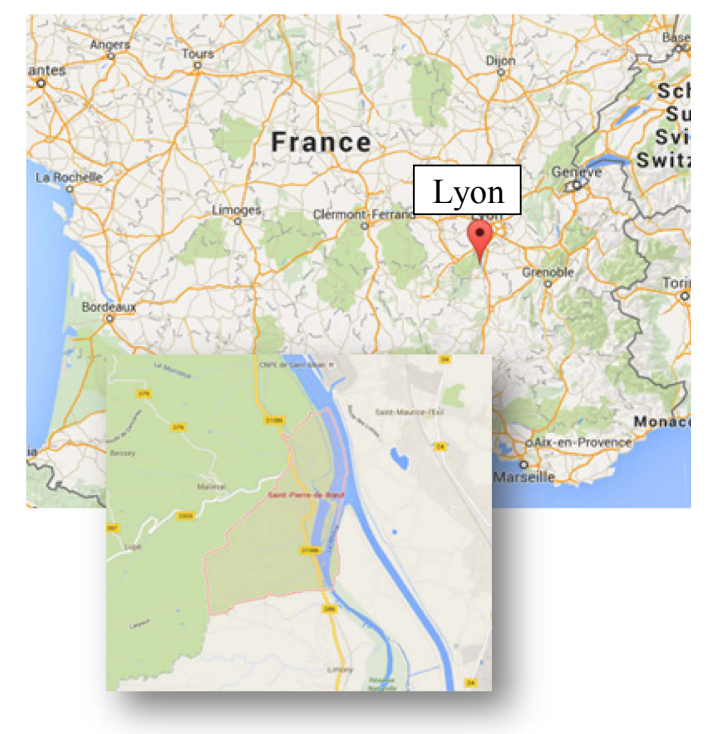

Figure 2 : location of the natural soil 


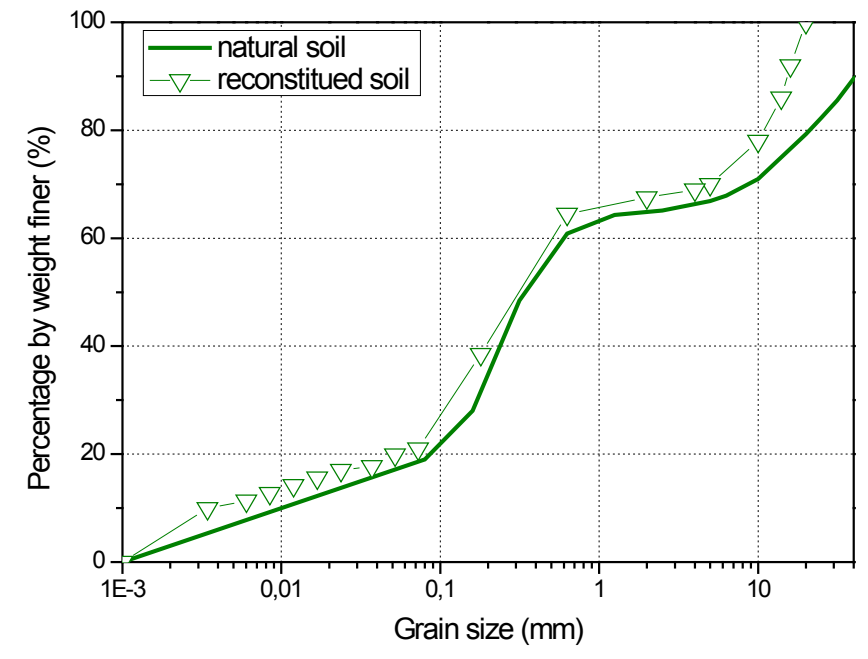

Figure 3. Grain size distribution of tested soils

The reconstitution in the laboratory is done by mixing the gravel, sand and the fine part with welldefined proportions. The fine part consists of kaolinite and sand (sand particles of size less than $80 \mu \mathrm{m}$ ). Rounded gravel have been split into fractions 31.5/20, 20/16, 16/14, 14/10, $10 / 6.3,6.3 / 4$ (Figure 4) as recommended by the French standard NF P 98230-3.

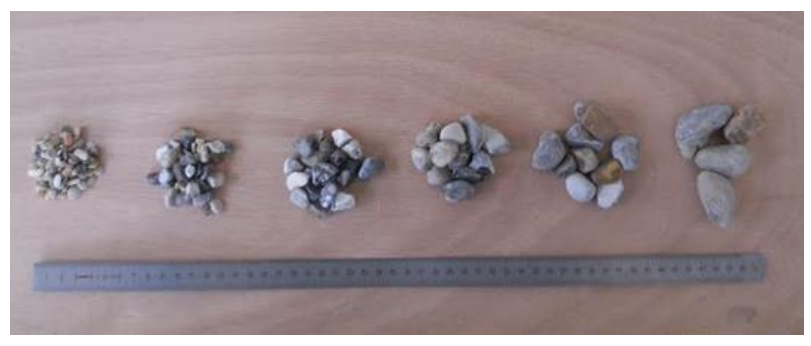

Figure 4 . Gravel washed and fractionated

The sand is a Hostun sand separated into several fractions namely $\mathrm{HN} 2 / 4, \mathrm{HN} 0.4$ / 0.8, HN $31 \mathrm{HN}$ 34 HN 38 (Table 1).

Table 1 : Characteristics of used sand

\begin{tabular}{lccc}
\hline Sable & $\boldsymbol{d}_{\mathbf{5 0}}(\boldsymbol{\mu m})$ & $\mathbf{C}_{\mathbf{u}}$ & Distribution \\
\hline Hostun HN 2/4 & 2849 & 1.4 & uniform \\
Hostun HN 0.4/0.8 & 596 & 1.5 & uniform \\
Hostun: HN 31 & 314 & 1.3 & uniform \\
Hostun: HN 34 & 211 & 1.6 & uniform \\
Hostun HN 38 & 113 & 2.3 & uniform \\
\hline
\end{tabular}

The thin portion ( $\mathrm{d}<80$ micrometers) consists of $40 \%$ of kaolinite $(\mathrm{k})$ and $60 \%$ ground sand $(\mathrm{C} 4)$ having the characteristics indicated in Table 2.
Table 2. Characteristics of the fine soils used

\begin{tabular}{|c|c|c|}
\hline & Characteristics & $\mathrm{C} 4-\mathrm{k}$ \\
\hline \multirow[t]{3}{*}{ Atterberg limits } & Liquid limit $\omega_{1}(\%)$ & 33 \\
\hline & Plastic limit $\omega_{p}(\%)$ & 21 \\
\hline & Plasticity index $\mathrm{I}_{\mathrm{P}}$ & 12 \\
\hline \multirow{3}{*}{$\begin{array}{l}\text { Grain size dis- } \\
\text { tribution }\end{array}$} & $<80 \mu \mathrm{m}$ & $65 \%$ \\
\hline & $<2 \mu \mathrm{m}$ & $30 \%$ \\
\hline & $\mathrm{D}_{60}(\mu \mathrm{m})$ & 60 \\
\hline
\end{tabular}

The lime used in this study is quicklime, commercially named Proviacal ST and provided by Lhoist Company. The characteristics of this lime are indicated in Table 3. An X-ray analysis showed the presence of calcite (Figure 5) indicating that this lime is a partially carbonated lime.

Table 3 . Lime characteristics

\begin{tabular}{ll}
\hline Characteristics & Value at $20^{\circ} \mathrm{C}$ \\
\hline Bulk density $(\mathrm{t} / \mathrm{m} 3)$ & $0,7-1,3$ \\
\hline $\mathrm{pH}$ on saturated solution & 12,3 \\
\hline
\end{tabular}

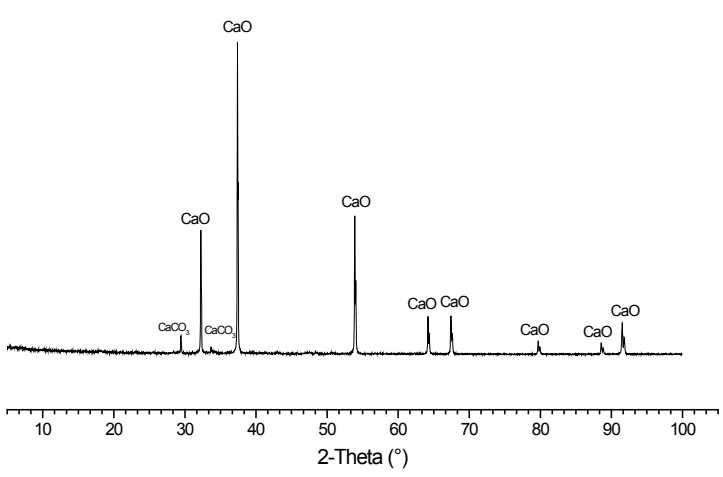

Figure 5. X-ray diffraction for lime

In order to prepare the untreated soil sample, with a compaction at $95 \%$ of the optimum Proctor on the wet side (13\% water content) (Figure 6), the different necessary proportions of sand, kaolinite and water are mixed during 3 minutes - speed 1 (70 rev / $\mathrm{min}$ ), the gravels are added and mixed with the rest by hand. Once the sample is prepared, it is kept in airtight bags for 24 hours for maturation. 


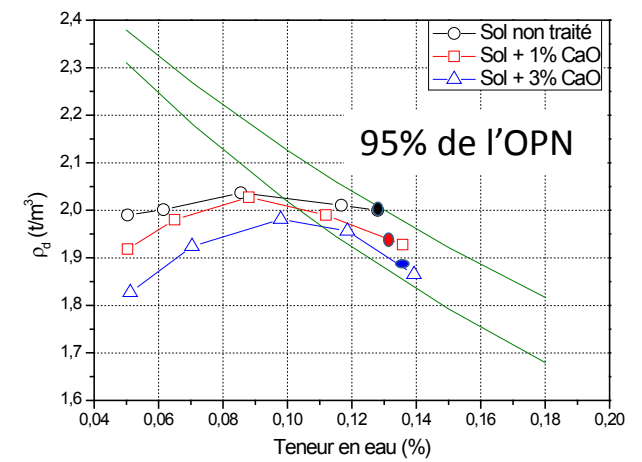

Figure 6 . Modified Proctor curve

For lime treated soil, the procedure is similar except few differences. After 24 hours of storage, the mixture "sand - kaolinite - water" is mixed again by adding lime. Then the proportion of gravel is added to the previously set for the dry density corresponding to $95 \%$ of the optimum Proctor (Figure 6). After further mixing, the mixture is kept for one hour before the compaction. The compaction of the sample in the suffusion column is done manually by compacting two layer of $8 \mathrm{~cm}$ with a normal Proctor hammer. The soil sample is disposed on a metal grid, placed itself on a gravel layer of approximately $1 \mathrm{~cm}$ in diameter. A fine filter placed between the grid and the soil sample avoids a loss of fine particles. Once the reconstituted sample is done and the tubing circuit is saturated, the test circuit is closed. The saturation of the sample is started by applying a low hydraulic gradient of approximately 1 .

\section{EXPERIMENTAL RESULTS}

In this section, we present in detail the results of two typical tests performed for untreated soil and for treated soil with $1 \%$ of lime and $24 \mathrm{~h}$ of curing time. The effects of percentage of lime and curing time are discussed.

\subsection{Untreated soil}

In this part, we will identify and help to explain the initiation and development of internal erosion processes observed in the case of untreated soil subjected to an upward unidirectional flow.

The Figure 7 presents the time evolution of pressure on the three sensors $\mathrm{C} 1, \mathrm{C} 2, \mathrm{C} 3$. A decrease in pressure is recorded after $5 \mathrm{~min}$ of applying the gradient $\mathrm{I}=3$.

This decrease is more pronounced at the $\mathrm{C} 3$ sensor located at the bottom of the sample.

This drop of pressure at the entrance of the sample may be explained by first a detachment and erod- ed particles and then a massive departure of particles allowing the free passage of the water, the flow water increase immediately from zero to $1,5 \mathrm{~cm} 3 / \mathrm{s}$.

The Figure 7 shows the evolution of the phenomenon over the time.

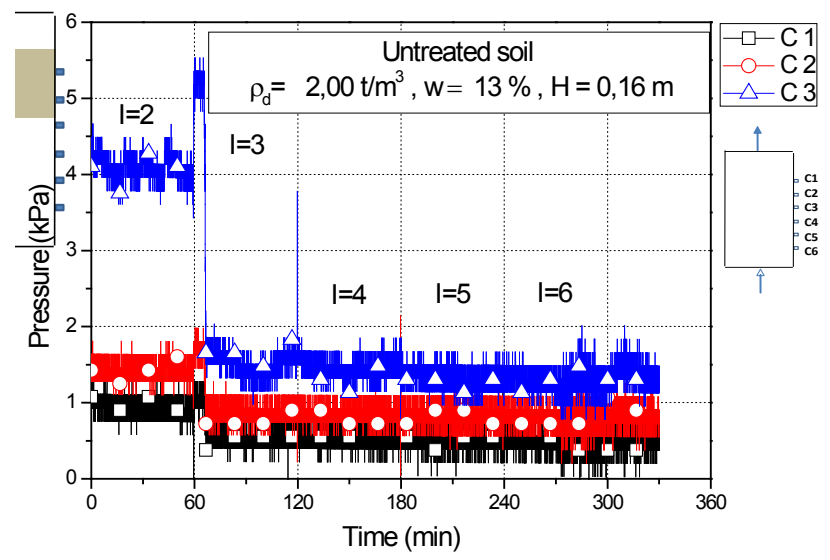

Figure 7 : Evolution of pressure during the loading phase for the untreated soil

Table 4 . Pictures of the simple taken at the end of the test

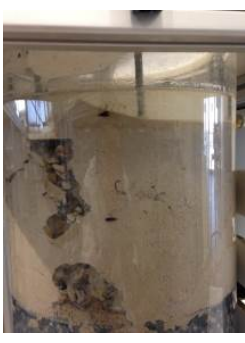

Front face

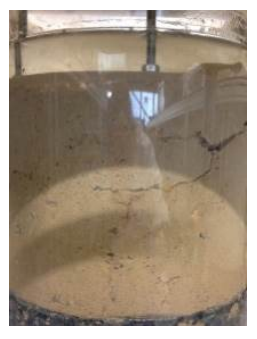

Lateral face

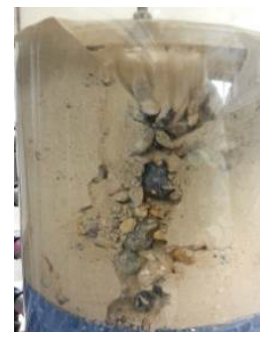

Back side
At the end of the test, the cumulative weight calculated by the recorded of turbidity and flow water indicates $79 \mathrm{~g}$. An $\mathrm{X}$ ray diffraction analysis showed that the eroded particles are a kaolinite (Figure 8).

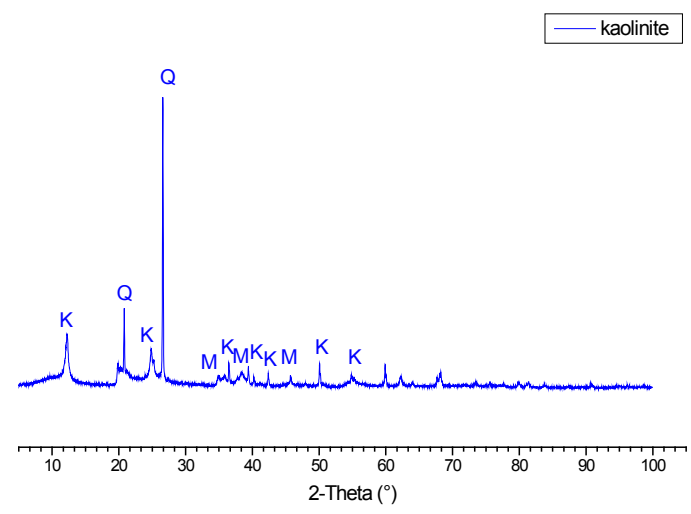

Figure 8. X-ray diffraction of the eroded particles 


\subsection{Treated soil}

The evolution of pressure recorded by the three pressure sensors are presented in Figure 9. Six levels of hydraulic gradient from level 2 to 7) have been applied on the sample. The first hydraulic gradient is not shown on the graph because it represents the saturation step. There is a drop in pressure at the sensor 1 during the application of the gradient 5. This decrease may be due at the beginning of the fracturing. This fracture, which is not visible to the eye, creates a flow path for the preferential water, liberating the pressure.

At the gradient 6, small fractures appear in the sample until the uplift of a portion of specimen creating a pocket of water (Figure 10).

It should be noted that the first cracks, visible to naked eye, always appears at the top. This can be explained by a downstream clogging (the particles are carried downstream where they are accumulated) causing a sudden drop pressure in the crack area.

Through time, the crack disappears when the system pressure has stabilized; this crack is replaced by other cracks. These latter appear in the lower part of the sample and open and close during the destruction of the sample structure until the occurrence of a large crack through the entire cross surface of the sample. This large crack expands creating a pocket of water then a sudden elevation of the part of the soil above the fracture is observed. The Figure 11 shows the evolution of the phenomenon since the beginning of loading until the uplifting of a portion of the sample.

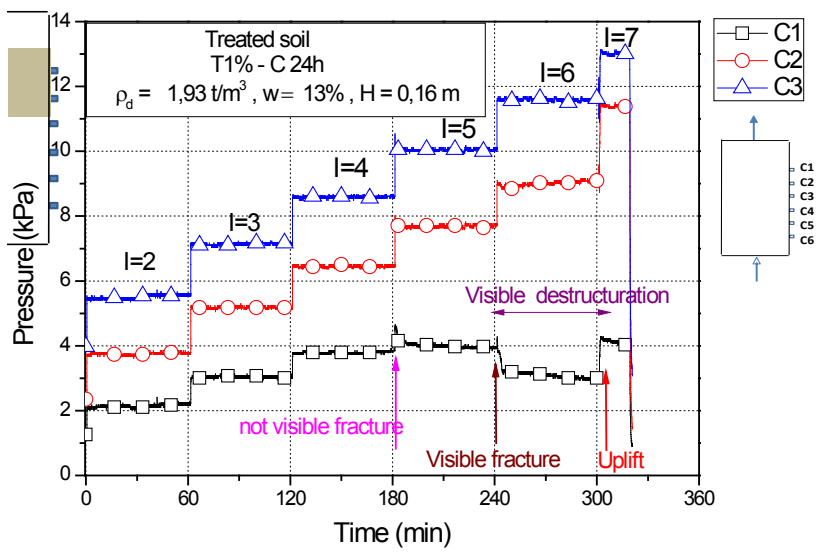

Figure 9. Evolution of pressure during the loading phase for the treated soil with $1 \%$ of lime and $24 \mathrm{~h}$ of curing time

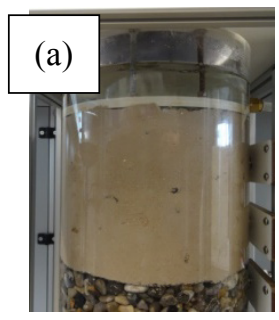

Before fracture

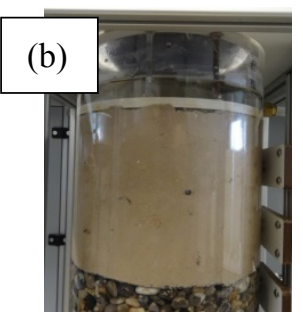

Visible fracture

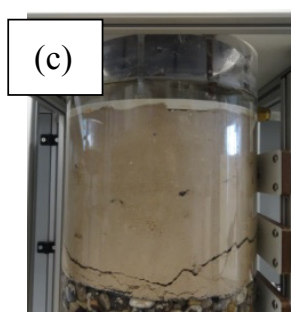

uplift
Figure 10. Evolution of the fracturing
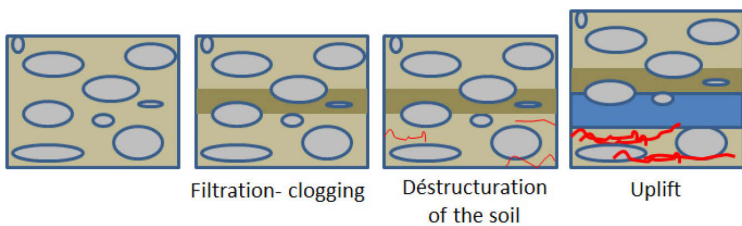

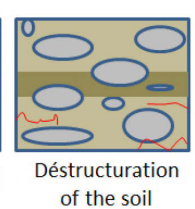

Figure 11. Schematization of the evolution of the phenomenon observed

This split is defined as the excess of the hydraulic pressure compared to the total overburden stress under the impermeable layer. So the effective vertical stress becomes zero causing an appearance of a pocket of water causing a progressive rising of the ground surface, of up to the breaking of this ground layer.

A balance sheet stresses is needed to better understand the start conditions of this phenomenon.

$$
P=\sigma_{v}
$$

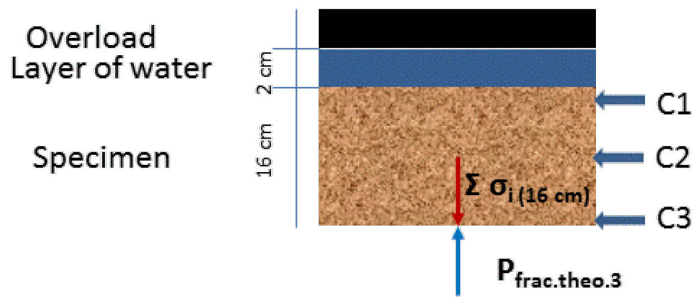

Figure 12. Diagram expressing stresses assessments

At the bottom of the sample, theoretical fracturing pressure resulting from the stress balance sheet is 5 , $3 \mathrm{kPa}$. However the measured fracturing pressure recorded on the sensor 3 is higher; a pressure of 10 $\mathrm{kPa}$ is recorded. It represents about twice the theoretical fracture pressure. This increase can be explained by the immediate effect brought by the lime treatment. 


\subsection{Effect of lime dosing and curing time}

In this part, we are interested on the effect of lime dosing and curing time on the occurrence of the phenomenon.

In the Figure 13, we observe that the addition of lime, even at low percentage $(1 \%$ of $\mathrm{CaO})$, brings immediate changes to the material (in the first seven days of treatment).These changes result in an increase in the hydraulic pressure required to break the soil by hydraulic breakdown (pressure applied at the bottom of the sample) so-called measured fracturing pressure.

It should be noted that during the first seven days, the destruction of the material takes place gradually with appearance, at first, of small cracks followed by an uplift of a portion of the sample and the formation of pocket water.

At 28 days, a decrease of the measured fracturing pressure is observed. This observation can be explained by a physico-chemical phenomenon mentioned by Maubec (2010): at the first day of treatment, the cement products are not yet fully developed and immediate effect brought by the flocculation treatment decreases.

At 90 days of curing, the destruction is sudden with a slight increase of the breakdown strength compared to that developed after 28 days of cure.

At 365 days of curing, no cracks are visible (even at the greatest gradient that could apply the device $\mathrm{I}=19$, corresponding to a pressure of $30 \mathrm{kPa}$ at the sensor 3). It should be noted that the $\mathrm{pH}$ measured at the end of the test is about 9.5 (close to the clean water used in the laboratory 8,75$)$.

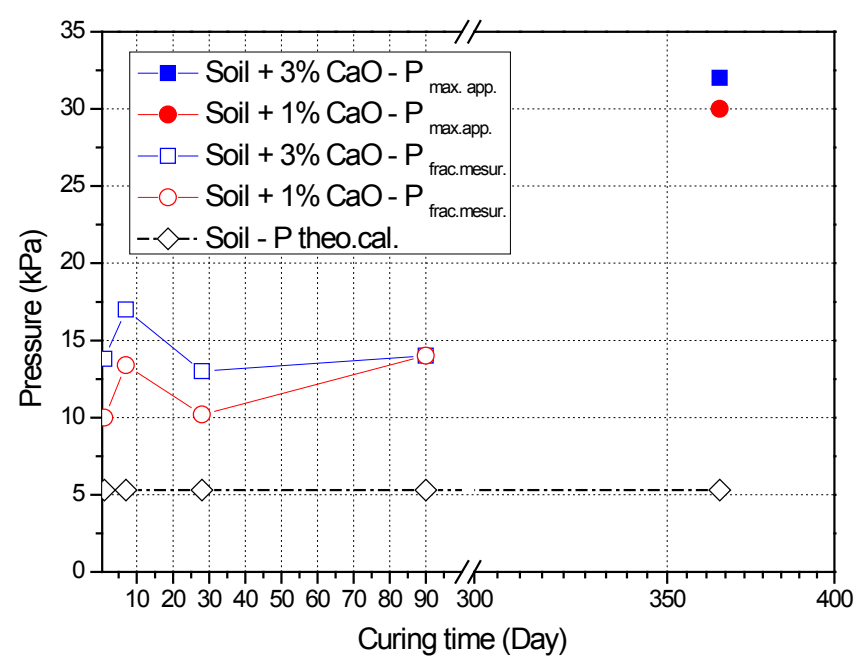

Figure 13.Evolution of the split off pressure at the sensor 3

\section{CONCLUSION}

In this work, an experimental study was conducted on the process of detachment and transport of particles by suffusion using an experimental setup developed for this study.

In order to improve the resistance to internal erosion by suffusion of an unstable coarse soil, a treatment of lime has been adopted.

The effects of significant parameters characterizing the improvement of suffusion process (such as the percentage of lime treatment and the duration of curing time) were studied.

Typical results have been described on tests performed on the untreated soil and on soil treated with $1 \%$ of lime and $24 \mathrm{~h}$ of curing time. A significant change in behavior has been observed. In the case of the untreated soil a solid particles migration is observed from gradient 4 corresponding to the beginning of suffusion.

The behavior of the $1 \%$ lime treated soil during the test is very different from that of the untreated soil. A decrease of pressure has been observed at gradient 5. This decrease is due to the beginning of the fracturing. This fracture, not visible to the eye, creates a flow path for the preferential water and liberates the pressure.

The same behavior had been observed and confirmed with another specimens treated for longer curing time (7, 28, 90 days) and different amount of lime $(1 \%$ and $3 \%)$. We observed a fracturing of the specimens at close pressure for each amount of lime. We can precise that the behavior, at the $90^{\text {th }}$ first days of curing, is governed by the phenomenon of flocculation witch bring more cohesion between the particles. At 365 days of curing time, no cracks are visible at the pressure max applied by the device. We can conclude that the lime treatment could be a solution to reduce or prevent suffusion phenomenon in these coarse soils.

\section{ACKNOWLEDGMENTS}

The authors gratefully acknowledge FNTP for supporting this research.

\section{REFERENCES}

AFNOR (1993). NF P 98-230-3. Essais relatifs aux chaussées : Préparation des matériaux traités aux liants hydrauliques ou non traités - Partie 3: Fabrication en laboratoire de mélange de graves ou de sables pour la confection d'éprouvettes. Recueil Normes Géotechniques, AFNOR.

Burenkova V. (1993). Assessment of suffusion in non-cohesive and graded soils. In the 1st International Conference Geo- 
filters, 357-360. Karlsruhe, Germany, Belkema, Rotterdam, The Netherlands.

De Bel I. R., Gomes Correia A., Duvigneaud P. H., François B., Herrier G., Verbrugge J. C. (2013) Evolution mécanique et physico-chimique à long terme d'un sol limoneux traité à la chaux. Colloque TerDOUEST 2013.

Haghighi I. (2012).Caractérisation des phénomènes d'érosion et de dispersion des sols : Développement d'essais et applications pratiques. Thèse de doctorat. Université Paris-Est.

Josseaume H. (1970). Digues en terre.- Bulletin laboratoire Ponts et Chaussées. Numéro Spécial (Hydraulique des sols).

Kenney T.C., Lau D. (1985). Internal Stability of Granular Filters. Canadian Geotechnical Journal 22, No. 2, 215-225.

Kezdi A. (1969). Increase of Protective Capacity of Flood Control Dikes. Department of geotechnics, Technical university of Budapest.

Li M. (2008). Seepage Induced Instability in Widely Graded Soils. Thèse de doctorat. The University of British Columbia.

Maubec N. (2010). Approche multi-échelle du traitement des sols à la chaux, études des interactions avec les argiles. Thèse de doctorat. Université de Nantes.

Terzaghi K. (1939). Soil Mechanics : A New Chapter in Engineering Science. Journal of Civil Engineering No.12: 106141. 